\title{
Dabigatran Etexilate and Digoxin: Comparison as Clinical Probe Substrates for Evaluation of P-gp Inhibition
}

DOI:

10.1002/cpt.2018.104.issue-5

\section{Document Version}

Accepted author manuscript

Link to publication record in Manchester Research Explorer

\section{Citation for published version (APA):}

Chu, X., Galetin, A., Zamek-gliszczynski, M. J., Zhang, L., \& Tweedie, D. J. (2018). Dabigatran Etexilate and Digoxin: Comparison as Clinical Probe Substrates for Evaluation of P-gp Inhibition. Clinical Pharmacology \& Therapeutics, 104(5), 788-792. https://doi.org/10.1002/cpt.2018.104.issue-5

\section{Published in:}

Clinical Pharmacology \& Therapeutics

\section{Citing this paper}

Please note that where the full-text provided on Manchester Research Explorer is the Author Accepted Manuscript or Proof version this may differ from the final Published version. If citing, it is advised that you check and use the publisher's definitive version.

\section{General rights}

Copyright and moral rights for the publications made accessible in the Research Explorer are retained by the authors and/or other copyright owners and it is a condition of accessing publications that users recognise and abide by the legal requirements associated with these rights.

\section{Takedown policy}

If you believe that this document breaches copyright please refer to the University of Manchester's Takedown Procedures [http://man.ac.uk/04Y6Bo] or contact uml.scholarlycommunications@manchester.ac.uk providing relevant details, so we can investigate your claim.

\section{OPEN ACCESS}




\title{
Dabigatran Etexilate and Digoxin: Comparison as Clinical Probe Substrates for Evaluation of P-gp Inhibition
}

\author{
Xiaoyan $\mathrm{Chu}^{1}{ }^{*}$, Aleksandra Galetin ${ }^{2}$, Maciej J. Zamek-Gliszczynski ${ }^{3}$, Lei Zhang ${ }^{4}$, and Donald J. \\ Tweedie $^{5}$ \\ on behalf of the International Transporter Consortium
}

1. Department of Pharmacokinetics, Pharmacodynamics and Drug Metabolism, Merck \& Co., Inc, Kenilworth, New Jersey 07033, USA; xiaoyan_chu@merck.com; 732-594-0977.

2. Centre for Applied Pharmacokinetic Research, School of Health Sciences, The University of Manchester, Stopford Building, Oxford Road, Manchester M13 9PT, UK; aleksandra.galetin@manchester.ac.uk; +44-161-275-6886

3. Quantitative Drug Disposition, GlaxoSmithKline plc, 709 Swedeland Road, King of Prussia, PA, 19406, USA; maciej.x.zamek-gliszczynski@gsk.com; 610-270-6278

4. Office of Research and Standards, Office of Generic Drugs, Center for Drug Evaluation and Research, Food and Drug Administration, 10903 New Hampshire Ave, Silver Spring, MD 20993, USA; leik.zhang@fda.hhs.gov; 301-796-1635

5. Department of Pharmacokinetics, Pharmacodynamics and Drug Metabolism, Merck \& Co., Inc, Kenilworth, New Jersey 07033, USA; donald.tweedie@merck.com; 215-652-5680.

* Corresponding Author:

Xiaoyan Chu, Ph.D.

RYN800-B210

126 East Lincoln Ave

Merck \& Co., Inc

Rahway, NJ, 07065, USA

Tel: 732-594-0977

E-mail: xiaoyan_chu@merck.com 
1 Words: $1763 / 1760$ words

2 Introduction: $75 / 75$ words

3 Figures/Tables: $2 / 2$

6 Conflict of Interest: The authors declared no competing interests for this work.

8 Funding: No funding was received for this work.

10 Disclaimer: The contents of this manuscript reflect the views of the authors and should not be

11 construed to represent the FDA's views or policies. No official support or endorsement by the

12 FDA is intended or should be inferred. The mention of commercial products, their sources, or

13 their use in connection with material reported herein is not to be construed as either an actual or

14 implied endorsement of such products by the FDA.

16 Abbreviations: absorption, distribution, metabolism, and excretion (ADME), area under the

17 concentration-time curve (AUC), carboxylesterase (CES), drug-drug interaction (DDI),

18 dabigatran etexilate (DE), maximum concentration $\left(\mathrm{C}_{\max }\right)$, maximal theoretical gut concentration

$19\left(\mathrm{C}_{\text {gut }}\right)$, organic solute transporter (OST), P-glycoprotein (P-gp), Uridine 5'-diphospho-

20 glucuronosyltransferase (UGT) 


\section{Introduction ( $75 / 75$ words)}

2 P-glycoprotein inhibition is part of routine DDI investigation in drug development. Selection of 3 P-glycoprotein clinical probes depends on selectivity, sensitivity, and co-medication relevance.

4 Traditionally this DDI was assessed clinically using digoxin, primarily due to safety concerns. 5 Digoxin is neither a specific, nor sensitive P-glycoprotein probe. Dabigatran etexilate (DE) has 6 been proposed as an alternative to study intestinal P-glycoprotein inhibition. Comparison of 7 digoxin and DE reveals key aspects of their suitability and limitations as P-glycoprotein probes. 
1 P-glycoprotein (P-gp) is a drug transporter recommended by regulatory agencies for clinical

2 evaluation as its inhibition can cause clinically important drug-drug interactions (DDIs) (1).

3 Although P-gp is localized at the apical membrane of multiple tissues (e.g., intestine, kidney,

4 liver and the blood brain barrier), inhibition of intestinal P-gp appears to have the most 5 significant impact on DDIs (1).

Ideally, a clinical probe to study intestinal P-gp inhibition should exhibit high selectivity and sensitivity. Specifically such a probe should 1) be mainly transported by P-gp, and 2) exhibit primarily P-gp-limited intestinal absorption with low-to-moderate fraction absorbed, 3) be

10 minimally metabolized, and 4) have sufficient clinical safety margin for exposure changes with

11 P-gp inhibitors. Practically, clinical probes need to be commercially available with appropriate 12 analytical assays for quantification.

14 Digoxin, a narrow therapeutic index drug, is a well-known P-gp substrate $(1,2)$. Digoxin DDI 15 studies have been routinely conducted in the development of drugs that are P-gp inhibitors. 16 However, digoxin is not selective for P-gp in vitro and in vivo, and exhibits low pharmacokinetic 17 (PK) sensitivity to P-gp inhibition with a reasonably high oral bioavailability (60-80\%) (2). As 18 such, it is not an ideal probe substrate for studying intestinal P-gp. Digoxin DDI study is 19 clinically relevant for the safe use of digoxin, however, it does not capture the true "worst-case" 20 victim DDI potential due to intestinal P-gp inhibition that may be used to predict potential DDI 21 effect on other P-gp substrate drugs. Recently, dabigatran etexilate (DE), a prodrug of 22 dabigatran, has been recommended by regulatory agencies as a clinical probe for studying 23 intestinal P-gp inhibition (3). The objective of this commentary is to compare the key features, 24 suitability, and limitations of DE and digoxin as clinical probes to study intestinal P-gp 25 inhibition. The information may help determine which probe should be used to study DDIs if a 26 new drug under development is a P-gp inhibitor.

28 Selectivity of DE and digoxin as P-gp probes: Comparison of their absorption, distribution, metabolism, and excretion (ADME) and transporter profiles

30 DE is rapidly absorbed and converted to parent dabigatran by carboxylesterases CES2 (in the 31 intestine) and CES1 (in the liver) (Figure 1A, NDA 022512, Drugs@FDA). Oral bioavailability 
1 of dabigatran following DE administration is 3-7\%, likely due to low intestinal absorption of DE

2 limited by P-gp efflux. Dabigatran is $80-85 \%$ eliminated unchanged in urine primarily via

3 passive glomerular filtration, is not metabolized by cytochrome P450 enzymes, but undergoes

4 glucuronidation in the liver to form pharmacologically active acyl glucuronides ( $10 \%$ of total

5 dabigatran following intravenous administration of $\mathrm{DE}$ ), which are eliminated in the urine.

6 Dabigatran is not transported by P-gp, and therefore DE is solely a probe for intestinal P-gp.

8 In contrast, digoxin exhibits much higher bioavailability (60-80\% as LANOXIN tablets), 9 substantially limiting its DDI sensitivity (defined below) as a result of P-gp inhibition. P-gp is 10 involved in digoxin intestinal, urinary, and biliary efflux (2). Following intravenous 11 administration, digoxin is eliminated via renal (50-70\%), hepatobiliary (10-30\%) excretion, as 12 well as intestinal secretion (10-20\%), with minimal metabolism. Thus, the alteration of systemic 13 exposure of digoxin by P-gp inhibitor drugs may not be solely attributed to P-gp-limited 14 intestinal absorption.

16 DE and digoxin also exhibit different transporter profiles (Figure 1B). In addition to P-gp,

17 digoxin undergoes basolateral uptake by an unidentified sodium-dependent uptake process both 18 in vitro and possibly in vivo; furthermore, sodium-independent organic anion transporting 19 polypeptide (OATP)4C1 mediates digoxin uptake into the renal proximal tubule (2). 20 Additionally, digoxin is known as a substrate of OST $\alpha / \operatorname{OST} \beta$, but their role in digoxin 21 disposition in vivo is unclear (Figure 1B). In contrast, DE is a more specific substrate for P-gp 22 and not transported by other major efflux transporters expressed in the intestine. Dabigatran is 23 not a substrate of major drug transporters. Transporter mechanisms of dabigatran glucuronides 24 are not known but are expected to have limited impact on dabigatran PK, as glucuronidation is a 25 minor elimination pathway.

27 Sensitivity of DE and digoxin as P-gp probes: Comparison of clinical P-gp inhibition 28 studies using DE and digoxin as probes

29 The sensitivity of a probe drug refers to the fold change in plasma AUC and/or $\mathrm{C}_{\max }$ in the 30 presence of an inhibitor relative to control and is an important consideration when selecting 31 clinical DDI probes. Table 1 summarizes in vitro P-gp inhibition data using DE as a probe and 
1 clinical DDIs evaluated with both digoxin and DE under similar dosing regimens of the 2 perpetrator drugs (3). The magnitude of a DDI using digoxin as a probe is generally low.

3 However, these changes are of clinical relevance to digoxin safety, where even a small increase

4 in exposure (e.g., 25-50\%) could represent a safety risk (NDA 020405, Drugs@ FDA).

6 Somewhat unexpected, except for cobicistat and glecaprevir/pibrentasvir, the magnitude of DDIs 7 using a therapeutic dose of DE is generally comparable to digoxin, despite relatively higher 8 selectivity of DE as a P-gp probe based on available in vitro and ADME data (Table 1). DE is a 9 high affinity P-gp substrate with an apparent $\mathrm{K}_{\mathrm{m}}$ of $\sim 1 \mu \mathrm{M}$ (4). At the therapeutic dose of DE (75$10150 \mathrm{mg})$, maximal theoretical gut concentrations $\left(\mathrm{C}_{\mathrm{gut}}=\mathrm{dose} / 250 \mathrm{ml}\right)$ of $\mathrm{DE}$ are approximately $11480-950 \mu \mathrm{M}$, which is below its aqueous solubility limit of $1.8 \mathrm{mg} / \mathrm{ml}(2.8 \mathrm{mM})$, but could be 12 above its solubility in neutral and basic conditions, due to its $\mathrm{pH}$-dependent dissolution (NDA 13 022512, Drugs@FDA). At therapeutic doses of DE, intestinal P-gp is most likely saturated,

14 reducing the effect of P-gp in DE absorption and lowering the DDI magnitude/sensitivity. In 15 contrast, digoxin is a low affinity P-gp substrate $\left(\mathrm{K}_{\mathrm{m}} \sim 177-220 \mu \mathrm{M}\right.$, Figure $\left.1 \mathrm{~B}\right)$, and P-gp is 16 unlikely to be saturated at its therapeutic dose $\left(0.25 \mathrm{mg} ; \mathrm{C}_{\mathrm{gut}}=1.28 \mu \mathrm{M}\right)$.

18 At a sub-therapeutic dose, $\mathrm{DE}$ is expected to be a more sensitive P-gp probe than digoxin or a 19 therapeutic dose of DE. A clinical microdose study has recently confirmed this hypothesis (5). 20 When DE was administered at a dose of $375 \mu \mathrm{g}\left(\mathrm{C}_{\mathrm{gut}}=2.4 \mu \mathrm{M}\right)$, rifampin, clarithromycin, and 21 itraconazole increased plasma AUC of dabigatran 2.4-, 4.2-, and 7.4-fold, respectively, with 22 comparable increase in $\mathrm{C}_{\max }$. Overall, the magnitude of DDIs observed was at least 2-fold higher 23 than at the therapeutic dose of DE, which can be explained by a DE microdose not saturating 24 intestinal P-gp (5).

\section{Challenges associated with $\mathrm{DE}$ as a P-gp probe}

27 The challenges associated with digoxin as a P-gp probe have been discussed previously $(1,2)$.

28 We therefore focus on DE in this Commentary.

29

$30 \quad$ Inter-individual $P K$ variability 
1 Dabigatran PK exhibits relatively high inter-individual variability, which fluctuated across

2 different studies and dosing regimens (the coefficient of variation of AUC ranged 30-60\%) (6).

3 Such variability might be attributed to inter-individual differences in P-gp and CES activities (7).

4 However, the impact of genetic polymorphisms of CES and P-gp on dabigatran PK in healthy

5 subjects is not fully confirmed and the effects of multiple coexisting genetic covariates in the same subject are not known. Furthermore, a pH-dependent dissolution of the mesylate salt of DE may also contribute to variability of intestinal absorption. PK variability of DE needs to be

8 considered when designing clinical DDI studies. Therefore, a cross-over study design and appropriate numbers of subjects are critical for DE P-gp DDI studies.

11 Carboxylesterase inhibition by perpetrator drugs

12 DE is hydrolyzed by CES to dabigatran (8, NDA 022512, Drugs@FDA). Clinical DDI data with

13 DE may be confounded if the perpetrator drugs also inhibit intestinal and/or hepatic CES. For

14 correct interpretation of clinical DE DDIs, pre-assessment of the inhibitory effects of a

15 perpetrator drug on CES activity needs to be considered.

\section{Stability of $D E$ in vitro}

18 DE is not stable in cell-based assays due to endogenous CES-catalyzed hydrolysis. Studies in 19 Caco-2 cells indicated that DE is stable if dosed in the basal, but not the apical compartment of 20 transwells, where DE has direct access to CES1 $(3,9)$. Similar results have been observed in P21 gp-transfected MDCKII and LLC-PK1 cells (Chu et al. unpublished data). Therefore, in vitro P$22 \mathrm{gp} \mathrm{IC}_{50}$ values for $\mathrm{DE}$ can be determined by monolayer flux only in the basal-to-apical direction

23 or as bi-directional transport in cells pretreated with esterase inhibitors (9). IC IC $_{50}$ values for 24 several P-gp inhibitors measured with DE for basal-to-apical transport predicted the risk for 25 DDIs with no false negatives (3) (Table 1). Further evaluations are needed to validate the assay 26 conditions, explore other assay systems (e.g., vesicles) and understand potential inter-lab 27 variability and its translational impact.

\section{Considerations in selection of a P-gp clinical probe for DDI assessment}

30 In clinical DDI studies, P-gp probes should be selected based on the specific DDI questions to be 31 addressed. DE may be a more selective probe than digoxin for the assessment of P-gp-mediated 
1 DDIs in the intestine. DE at a sub-therapeutic dose (e.g., microdose) is likely to provide a more 2 sensitive readout for intestinal P-gp DDIs due to lack of transporter saturation compared to 3 digoxin or DE therapeutic dose. In addition, a DE microdose can minimize safety concerns of 4 therapeutic dose of this oral anticoagulant agent in healthy subjects. Furthermore, a DE 5 microdose can potentially reduce $\mathrm{PK}$ variability (5) likely attributed to $\mathrm{pH}$-dependent dissolution.

6 On balance, a DE microdose evaluates the worst-case scenario for P-gp inhibition, and as such 7 represents the most sensitive clinical effect. However, the magnitude of the resulting DDIs 8 should not be directly extrapolated to a therapeutic dose of DE or other P-gp substrates as an 9 indicator of safety concerns or dose adjustment. It is envisaged that a qualified PBPK model for 10 DE can bridge this gap to support P-gp clinical DDI study design in the future. The feasibility of 11 conducting a DE microdose study can be limited by the sensitivity of analytical assays. 12 Compared to digoxin, in vitro and in vivo data using DE as a P-gp probe are still limited and 13 additional data are needed to verify in vitro to in vivo translation. In addition, DE will not be

14 suitable to study P-gp inhibition in other tissues when a potential P-gp inhibitor is a non-oral 15 drug.

17 Despite a lack of P-gp selectivity and sensitivity, digoxin DDI evaluation may still be warranted 18 to assess the risk of perpetrator drugs on digoxin safety due to its narrow therapeutic index. To 19 interrogate renal P-gp DDIs with digoxin, renal clearance would also need to be measured in the 20 DDI study.

22 In summary, a DE microdose is a more selective and sensitive P-gp probe than digoxin to study 23 inhibition of intestinal P-gp, with CES inhibition as a potential confounding factor. Clinical 24 digoxin DDI studies with P-gp inhibitors should primarily be conducted to ensure safe co25 medication. Additional in vitro and clinical studies with DE would greatly advance our 26 understanding of its suitability as a P-gp probe and investigators are encouraged to share these 27 data. 


\section{Acknowledgement}

2 The authors would like to acknowledge Dr. Xinning Yang for his valuable comments on the 3 manuscript. 


\section{Figure Legend:}

2 Figure 1. In vivo disposition of dabigatran etexilate (DE) and dabigatran in human (A) and 3 the comparison of their in vitro transporter profiles with digoxin (B)

4 DE ADME data are obtained from NDA 022512 (Drugs@FDA). DE, dabigatran, and digoxin in

5 vitro transporter data are obtained from the University of Washington DDI database

6 https://www.druginteractioninfo.org and reference 10.

$7 \quad$ a : UGT2B15 is more prominently expressed in the liver and is the major contributor to the

8 glucuronidation of dabigatran; UGT1A9 and UGT2B7 have minor contribution. The formation

9 of dabigatran acylglucuronides in the gut is low and their possible interplay with P-gp-mediated

10 DE efflux is therefore less likely.

11 b: It is not known whether DE is a substrate of intestinal uptake transporters. Since DE has

12 moderate to high passive permeability and DE can be converted to dabigatran by intestinal

13 CES2, the involvement of intestinal uptake transporters on absorption of DE could be limited.

14 Given that DE is almost completely converted to dabigatran pre-systemically, hepatic and renal

15 transporters are less likely involved in the disposition of DE.

$16{ }^{\mathrm{c}}$ : Transporter phenotyping data for dabigatran glucuronides have not been reported.

17 Abbreviations: OST $\alpha$, organic solute transporter- $\alpha$; OST $\beta$, organic solute transporter- $\beta$. 


\section{References}

(1) Agarwal S, Arya V, Zhang L. Review of P-gp inhibition data in recently approved new drug applications: utility of the proposed [I(1) ]/IC(50) and $[\mathrm{I}(2)] / \mathrm{IC}(50)$ criteria in the P-gp decision tree. Journal of clinical pharmacology $2013 \mathrm{Feb}$;53(2):228-33.

(2) Lee CA, Kalvass JC, Galetin A, Zamek-Gliszczynski MJ. ITC commentary on the prediction of digoxin clinical drug-drug interactions from in vitro transporter assays. Clinical pharmacology and therapeutics 2014 Sep;96(3):298-301.

(3) Kishimoto W, Ishiguro N, Ludwig-Schwellinger E, Ebner T, Schaefer O. In vitro predictability of drug-drug interaction likelihood of P-glycoprotein-mediated efflux of dabigatran etexilate based on [I]2/IC50 threshold. Drug metabolism and disposition: the biological fate of chemicals $2014 \mathrm{Feb} ; 42(2): 257-63$.

(4) Zhao Y, Hu ZY. Physiologically based pharmacokinetic modelling and in vivo [I]/K(i) accurately predict $\mathrm{P}$-glycoprotein-mediated drug-drug interactions with dabigatran etexilate. British journal of pharmacology 2014 Feb;171(4):1043-53.

(5) Prueksaritanont T, Tatosian DA, Chu X, Railkar R, Evers R, Chavez-Eng C, et al. Validation of a microdose probe drug cocktail for clinical drug interaction assessments for drug transporters and CYP3A. Clinical pharmacology and therapeutics 2017 Apr;101(4):519-30. (6) Ollier E, Hodin S, Basset T, Accassat S, Bertoletti L, Mismetti P, et al. In vitro and in vivo evaluation of drug-drug interaction between dabigatran and proton pump inhibitors. Fundamental \& clinical pharmacology 2015 Dec;29(6):604-14.

(7) Pare G, Eriksson N, Lehr T, Connolly S, Eikelboom J, Ezekowitz MD, et al. Genetic determinants of dabigatran plasma levels and their relation to bleeding. Circulation $2013 \mathrm{Apr}$ 2;127(13):1404-12.

(8) Laizure SC, Parker RB, Herring VL, Hu ZY. Identification of carboxylesterasedependent dabigatran etexilate hydrolysis. Drug metabolism and disposition: the biological fate of chemicals $2014 \mathrm{Feb}$;42(2):201-6.

(9) Ishiguro N, Kishimoto W, Volz A, Ludwig-Schwellinger E, Ebner T, Schaefer O. Impact of endogenous esterase activity on in vitro p-glycoprotein profiling of dabigatran etexilate in Caco-2 monolayers. Drug metabolism and disposition: the biological fate of chemicals 2014 Feb;42(2):250-6.

(10) Hodin S, Basset T, Jacqueroux E, Delezay O, Clotagatide A, Perek N, et al. In Vitro Comparison of the Role of P-Glycoprotein and Breast Cancer Resistance Protein on Direct Oral Anticoagulants Disposition. European journal of drug metabolism and pharmacokinetics 2017 Sep 11. 
Table 1 Examples of P-gp-related Clinical DDIs Using DE and Digoxin as Probe Substrates

\begin{tabular}{|c|c|c|c|c|c|c|c|}
\hline \multirow[b]{2}{*}{ Drugs } & \multicolumn{2}{|l|}{ Dose regimen } & \multirow[b]{2}{*}{$\begin{array}{l}\mathrm{IC}_{50} \\
(\mu \mathrm{M})^{\mathrm{a}}\end{array}$} & \multirow[b]{2}{*}{$\begin{array}{l}\mathrm{I}_{2} / \mathrm{IC} \mathrm{C}_{50} \\
\text { for } \mathrm{DE}\end{array}$} & \multirow{2}{*}{$\begin{array}{l}\text { \% Change of } \\
\text { Dabigatran } \\
\text { AUC }^{b, c}\end{array}$} & \multirow{2}{*}{$\begin{array}{l}\% \text { Change } \\
\text { of Digoxin } \\
\text { AUC }^{c}\end{array}$} & \multirow[t]{2}{*}{ References } \\
\hline & DE as probe drug & $\begin{array}{l}\text { Digoxin as } \\
\text { probe drug }\end{array}$ & & & & & \\
\hline Clarithromycin & $\begin{array}{l}500 \mathrm{mg}, \text { BID for } 4- \\
5 \text { days }\end{array}$ & $\begin{array}{l}500 \mathrm{mg}, \\
\text { BID for } 7 \\
\text { days }\end{array}$ & 28 & 36 & $49-114,302^{\mathrm{e}}$ & $35.1-68.2$ & $\begin{array}{l}3,5, \text { NDA } \\
022512 \\
\text { (Drugs@FDA) }\end{array}$ \\
\hline Verapamil & $\begin{array}{l}120 \text { mg } \\
\text { (immediate } \\
\text { release) SD or BID } \\
1 \mathrm{~h} \text { before or } \\
\text { concomitantly } \\
\text { with DE }\end{array}$ & $\begin{array}{l}\text { 80mg TID } \\
\text { for } 10 \text { days } \\
\text { following } \\
\text { BID for } 4 \\
\text { days }\end{array}$ & NR & NR & $39.3-142.5$ & 51 & $\begin{array}{l}\text { NDA } 022512 \\
\text { (Drugs@FDA) }\end{array}$ \\
\hline Amiodarone & $600 \mathrm{mg}$ SD & $\begin{array}{l}400-800 \\
\mathrm{mg} / \text { day for } \\
1 \text { week }\end{array}$ & $>10$ & $<470$ & 58 & $64-68$ & 3 \\
\hline Itraconazole & $\begin{array}{l}200 \text { mg capsule } \\
\text { QD for } 5 \text { days }\end{array}$ & $\begin{array}{l}200 \text { mg QD } \\
\text { for } 5 \text { days }\end{array}$ & 0.41 & 1100 & $117^{\mathrm{d}}, 592^{\mathrm{e}}$ & 68 & 3,5 \\
\hline Ketoconazole & $\begin{array}{l}400 \text { mg SD or } 400 \\
\text { mg QD for } 8 \text { days }\end{array}$ & & 3.4 & 880 & $138-153$ & $N R^{f}$ & $\begin{array}{l}3, \text { NDA } \\
022512 \\
\text { (Drugs@FDA) }\end{array}$ \\
\hline Quinidine $^{\mathrm{g}}$ & $\begin{array}{l}200 \mathrm{mg} \text { every } 2 \mathrm{~h} \\
(1000 \mathrm{mg} \text { in total) }\end{array}$ & $\begin{array}{l}600 \mathrm{mg} \text { BID } \\
\text { for } 8 \text { days }\end{array}$ & 33 & 150 & 53 & 166 & $\begin{array}{l}\text { 3, NDA } \\
022512 \\
\text { (Drugs@FDA) }\end{array}$ \\
\hline
\end{tabular}




\begin{tabular}{|c|c|c|c|c|c|c|c|}
\hline Dronedarone & 400 mg BID & $\begin{array}{l}400 \mathrm{mg} \text { BID } \\
\text { for } 10 \text { days }\end{array}$ & NR & NR & 130 & 133 & $\begin{array}{l}\text { NDA } 022512 \\
\text { (Drugs@FDA) }\end{array}$ \\
\hline Cobicistat & $\begin{array}{l}150 \mathrm{mg} \text { QD for } 22 \\
\text { days }\end{array}$ & $\begin{array}{l}150 \mathrm{mg} \text { for } \\
10 \text { days }\end{array}$ & NR & NR & $110-137$ & 8.8 & \\
\hline Glecaprevir/Pibrentasvir ${ }^{\text {h }}$ & $\begin{array}{l}\text { Glecaprevir } 300 \\
\text { mg/ } \\
\text { Pibrentasvir } 120 \\
\text { mg QD }\end{array}$ & $\begin{array}{l}\text { Glecaprevir } \\
400 \text { mg/ } \\
\text { Pibrentasvir } \\
120 \text { mg QD }\end{array}$ & NR & NR & 138 & 48 & $\begin{array}{l}\text { NDA } 209394 \\
\text { (Drugs@FDA) }\end{array}$ \\
\hline
\end{tabular}

$A U C$, area under the concentration-time curve; $D E$, dabigatran etexilate; DDI, drug-drug interaction; IC 50 , half maximal inhibitory concentration; $I_{2}$, concentration of inhibitor in the gastrointestinal tract based on dose divided by a volume of $250 \mathrm{~mL}$; NR, not reported.

${ }^{a}$ In vitro P-gp IC 50 data are obtained from Caco-2 cells using DE as substrate; ${ }^{\mathrm{b}} \mathrm{DE}$ clinical dose range $75-300 \mathrm{mg}$; total dabigatran (dabigatran plus its glucuronide) was measured in clinical DDI studies with amiodarone, ketoconazole, quinidine, verapamil, and dronedarone. ${ }^{\circ} \mathrm{Clinical}$ DDI data are obtained from the University of Washington DDI database (https://www.druginteractioninfo.org) or specified in the references;

Unpublished data: itraconazole dosing regimen $200 \mathrm{mg}$ capsules QD for 5 days; ${ }^{\circ} \mathrm{DE}$ dose $375 \mu \mathrm{g}$ SD PO; digoxin DDls at microdose have not been reported ${ }^{\dagger}$ Clinical DDI data are only available at ketoconazole dose of $200 \mathrm{mg}$ QD for 4 days. ${ }^{9}$ Quinidine was administered in different dose regimen in these clinical DDI studies. Given that the gut is the major site for DDls with P-gp, quinidine exposure in the gut under these two study conditions can be different. ${ }^{\text {hBoth }}$ glecaprevir and pibrentasvir are in vitro inhibitors for P-gp. 
A.<smiles>CCCCCCCC(=O)N=C(N)c1ccc(NCc2nc3cc(C(=O)N(CCC(=O)O)c4ccccc4)ccc3n2C)cc1</smiles>
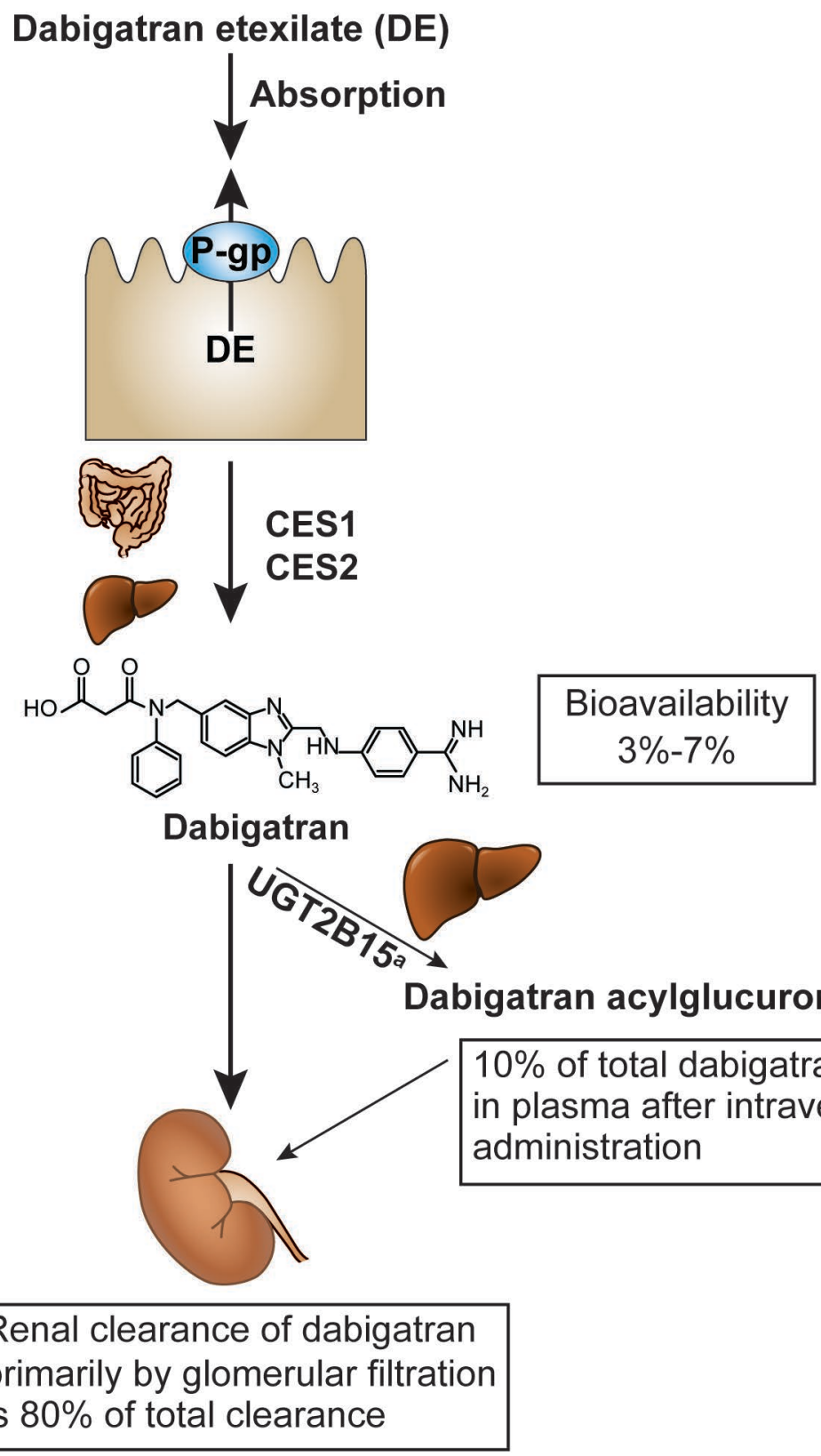

B.

\section{Renal clearance of dabigatran primarily by glomerular filtration is $80 \%$ of total clearance}

\begin{tabular}{|l|l|}
\hline \multicolumn{1}{|c|}{ Digoxin } & \multicolumn{1}{|c|}{$\mathrm{DE}$} \\
\hline $\begin{array}{l}\text { Substrate for P-gp }\left(\mathrm{K}_{\mathrm{m}} 177-220 \mu \mathrm{M}\right), \\
\text { OATP4C1 }\left(\mathrm{K}_{\mathrm{m}} 7.8 \mu \mathrm{M}\right), \text { OST } \alpha / \beta, \text { and } \\
\text { sodium-dependent uptake transporter(s) }\end{array}$ & Substrate for P-gp $\left(\mathrm{K}_{\mathrm{m}} 1 \mu \mathrm{M}\right)$ \\
\hline $\begin{array}{l}\text { Not a substrate for OATP1A2, OATP1B1, } \\
\text { OATP1B3, and OATP2B1 }\end{array}$ & Not a substrate for BCRP and MRP2 $\mathrm{b}$ \\
\hline $\begin{array}{l}\text { P-gp may contribute to intestinal } \\
\text { absorption, renal and hepatic elimination }\end{array}$ & $\begin{array}{l}\text { P-gp-mediated DDIs are restricted to } \\
\text { intestinal absorption of DE }\end{array}$ \\
\hline & $\begin{array}{l}\text { Parent drug dabigatran is not a substrate for P-gp, MRP2, } \\
\text { BCRP, OATP1B1, OATP1B3, OAT1, OAT3, and likely a } \\
\text { marginal substrate for OCT2 } \mathrm{c}\end{array}$ \\
\hline
\end{tabular}

